\title{
The role of information and communication technology in self-management of type 2 diabetes
}

\author{
Filip Krajnc, Maruša Magister, Klara Nartnik, Andrej Starc \\ University of Ljubljana, Faculty of Health Sciences, Zdravstvena pot 5, 1000 Ljubljana, Slovenia \\ krajncfilip@gmail.com, marusa.magister04@gmail.com, klaraaara@gmail.com, andrej. \\ starc34@gmail.com
}

\section{Abstract}

Introduction: Type 2 diabetes is a chronic disease which represents a substantial burden on healthcare across the world. The use of information and communication technology (ICT) in self-management of diabetes is becoming more common, as it enables effective selfmanagement and control over your health. Technology such as computers, smart phones, tablets and mobile apps can overcome time and location barriers by monitoring data such as blood glucose levels from home and can establish communication between patients and healthcare personnel. Previous studies have shown that despite numerous benefits, prevalence of ICT use in self-management of type 2 diabetes is low. Methods: The descriptive research method with a systematic literature review was used in the following databases: Google Schoolar, PubMed, CINAHL and Medline. The search proceeded with the help of Boolean logical operator AND, together with the key words: »Patient«, »Type 2 Diabetes«, »Self-management«, »Information and communication technology«. A systematic literature review was conducted in the first half of March 2020. PRISMA methodology was used to display decisions about usefulness of reviewed sources and seven of those sources were selected for further analysis. Results: Patients with type 2 diabetes are willing to use ICT and are aware of its benefits, but the prevalence remains low. Ignorance about computers, smart phones or more specifically mobile apps and the possibility of personal information breaches are the most common barriers to ICT use. Results show that the use of ICT contributes to a statistically significant reduction of glycated hemoglobin (HbA1c), however studies are divided about the reduction of body weight and body mass index (BMI). Patients want ICT to include different communication channels, enable possibilities for exchanging experiences and connection with different healthcare systems and to offer written and visual individualized information about their disease. 
Discussion and conclusions: Because the use of ICT enables simpler monitoring of diabetes and reduces the possibilities of complications, its use is becoming ever more necessary, due to the fast ageing population and an increasing rate of chronic disease. This way of self-managing disease will simplify medical treatment for patients living in the countryside because of faster and easier access to medical assistance. In addition, healthcare personnel will be relieved of unnecessary treatment and will be able to take preventative measures faster and more easily through continuous patient monitoring. Developing new ICT for the management of chronic diseases such as type 2 diabetes requires collaboration between healthcare personnel and ICT experts; in addition, we must consider the patient's wishes and needs.

Keywords: patient, type 2 diabetes, self-management, information and communication technology

\section{Introduction}

Type 2 diabetes mellitus $\left(\mathrm{T}_{2} \mathrm{DM}\right)$ is a chronic disease that represents a major cause of morbidity and mortality and has a substantial burden on healthcare across the world (WHO - World Health Organization, 2018). In 2019 the prevalence of diabetes was estimated to be $9,3 \%$ worldwide ( 463 million of people) and by 2030 they expect an increase to $10.9 \%$ (700 million of people) (Saeedi et al., 2019). Improperly managed diabetes leads to serious damage to the heart, blood vessels, eyes, kidneys, nerves, and limb amputation (WHO, 2018). Active and efficient management of diabetes, which can be exceedingly difficult (Nyenwe et al., 2011), is key to prevent or minimize these complications (CDC - Centers for Disease Control and Prevention, 2019). Information and communication technology (ICT) is generally defined as technology used to communicate, manipulate, and store data by electronic means (Perron et al., 2010). The use of ICT is becoming more common, as it enables effective self-management of diabetes, patient empowerment, and control over your health (Yamaguchi et al., 2019). ICT such as computers, smart phones, tablets, and mobile apps can overcome time and location barriers by monitoring data such as blood glucose levels from home (Arnhold et al., 2014), establish communication between patients and healthcare personnel and help patients learn more about their ongoing self-care (Cui et al., 2016).

\section{Methods}

We conducted a systematic literature review with a descriptive analysis of the sources. The literature was searched in the following databases: Google Scholar, PubMed, CINAHL, and Medline. Keywords used to search for relevant articles included: "Patient", “Type 2 Diabetes", "Self-management", and "Information and Communication Technology". The search proceeded with the help of Boolean logical operator AND for connecting the search terms. English-language articles, published between 2015 and 2020 that were available in full, 


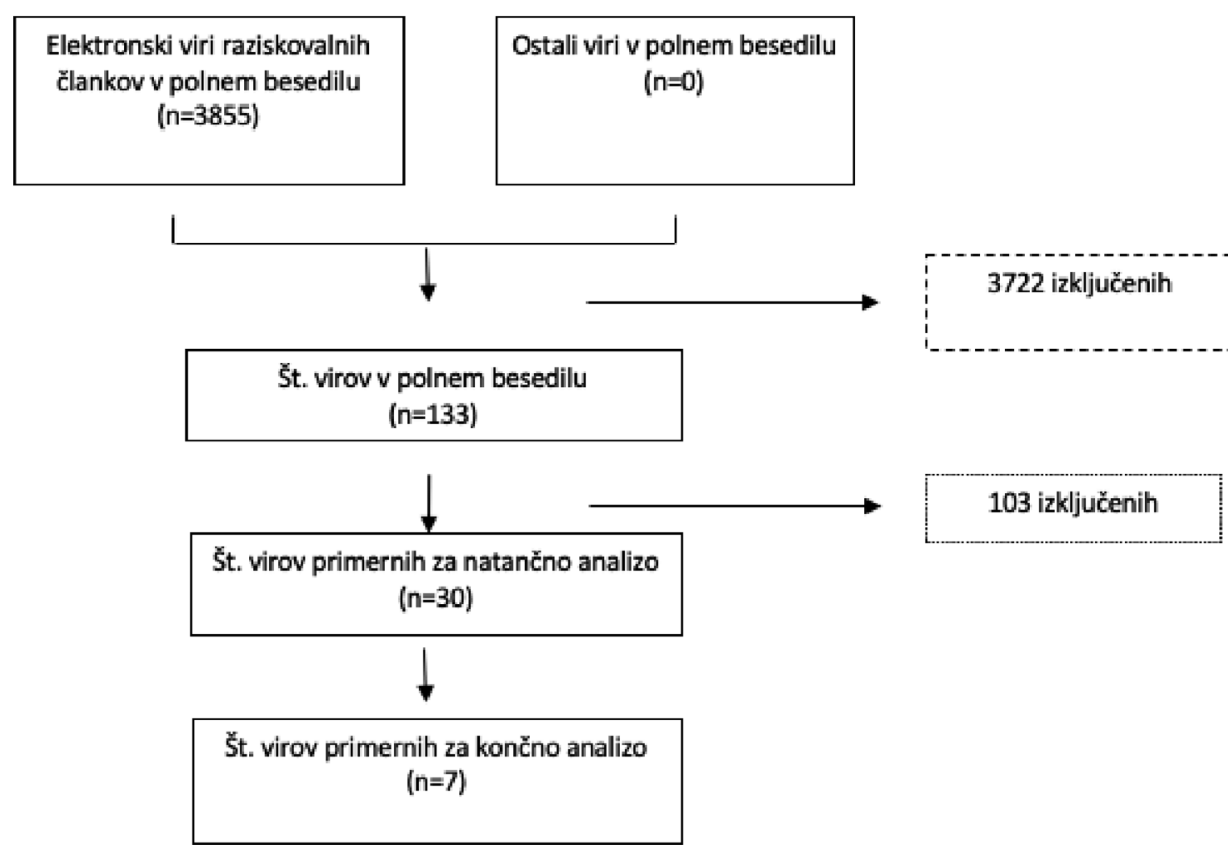

Figure 1: PRIZMA diagram

were identified and reviewed. PRISMA methodology (Figure 1) was used to display decisions about the usefulness of reviewed sources.

\section{Results}

Results of a descriptive analysis of the studies are presented in Table 1.

\section{Table 1: Overview of studies}

\begin{tabular}{|c|c|c|c|}
\hline Author & Purpose of research & Methodology & Results \\
\hline $\begin{array}{l}\text { Aminud- } \\
\text { din et al., } \\
2019\end{array}$ & $\begin{array}{l}\text { To determine the effective- } \\
\text { ness of smartphone-based } \\
\text { interventions. }\end{array}$ & $\begin{array}{l}\text { A systematic review } \\
\text { and meta-analysis. }\end{array}$ & $\begin{array}{l}\text { Participants who received } \\
\text { smartphone-based self-man- } \\
\text { agement intervention had } \\
\text { better self-efficacy, self-care } \\
\text { activities, health related qual- } \\
\text { ity of life and lower glycat- } \\
\text { ed haemoglobin compared } \\
\text { to the control group. The ef- } \\
\text { fects on body mass index and } \\
\text { blood pressure were not sta- } \\
\text { tistically significant. }\end{array}$ \\
\hline
\end{tabular}


To identify the ICT tools

Ayanlade used for diabetes manage-

et al., 2019 ment and assesses the level of and structured interviews. adoption of the tools.

ICT reduce health care personnel's workload and enable faster and easier completion of their daily tasks. Patients acknowledge the usefulness of ICT because it helps with their disease management plans.

ICT self-management service needs to offer different communication channels, possibilities for exchanging experiences and written and visualized individualized information.

Gardsten To identify patients' wishet al., 2017 es and needs for an ICT self-management service.
Participatory design: Future workshop method.

Patients had positive percep-

\section{Georgss-}

son and

Staggers,

2017

To understand patients per-
ceptions of using ICT for dia-

betes self-management.
Descriptive study us-

ing a questionnaire and semi-structured interview.
To evaluate impact of ICT

Lehocki et on clinical outcomes (glycatal., 2015 ed haemoglobin (HbA1c) and metabolic parameters)
Prospective, non-interventional, observational, multicentre study.
To identify the

Petersen et challenges and barriers for al., 2018 the adoption of ICT tools for diabetes self-management.
Qualitative study with semi structured interviews. tions toward ICT tool. After 6 months of using the ICT tool they saw clear benefits in using the technology and had favourable behavioural disease outcomes.

Clinical evaluation after 3 months of intervention showed statistically significant change of HbAic in both patient groups. Results also showed statistically significant tendency to decrease in weight and BMI.

Barriers to ICT adoption for diabetes self-management are: expensive ICTs, lack of technological literacy, participants' perceptions that mobile technologies are useless, the mistrust of technology and the preference for faceto-face interaction with medical staff.

Only $16 \%$ patients with diabetes currently use ICT and a total of $50 \%$ expressed the willingness to use ICT in future. Factors associated with

To examine the prevalence Shibuta et and patient characteristics asal., 2017 sociated with willingness to use ICT in self-management A cross-sectional interview survey. the willingness are not having nephropathy, outpatient visits once a month or more, current use of personal computers and/or smartphones and having greater diabetes related emotional distress.

\section{Discussion}

Prevalence of patients using ICT-based self-management tools is low (16\%) (Shibuta et al., 2016). The most common tools they used were applications, 
spreadsheet software and pedometer functions in mobile phones. On the other hand, most of the patients with type 2 diabetes were willing to use ICT-based tools in future and thought it is useful (Shibuta et al., 2016). In the study from Georgsson and Stagegers (2017) patients saw clear benefits in using the technology and had favourable behavioural disease outcomes after 6 months using ICT-based self-management tool. These types of tools were also accepted by the health care personnel, who claimed it helped them with continuous monitoring of the patient's health status, especially for patients that live in the countryside. It also helps take preventive measures sooner, relieve them unnecessary work and enables faster and easier accomplishment of their daily tasks (Ayanlade et al., 2019). Psychosocial factors which influence patients' willingness to use ICT are the patients' attitude toward ICT, the effectiveness and level of expected success of such technology, and the strive imported by the patients (Shibuta et al., 2016). Other factors associated with the willingness are not having nephropathy, frequent visits to diabetes physicians once a month or more and current use of personal computers and/or smartphones (Shibuta et al., 2016). Patients suggested that ICT should include different communication channels, enable possibilities for exchanging experiences and connection with different healthcare systems and to offer written and visual individualized information about their disease (Gardsten et al., 2017). Patients were unwilling to use an ICT based self-management tool because it seemed burdensome, difficult to use and too complex, especially for older patients. For some patients it seemed boring, ineffective, and too time consuming. Others thought that their current self-management activities were enough for them or their health condition did not allow them to use ICT based tools (Shibuta et al., 2016; Petersen et al., 2018). Other barriers included fear of data insecurity, mistrust of technology and the preference of face-to-face interaction with health care personnel (Petersen et al., 2018; Ayanlade et al., 2019). It was shown that patients found ICT based tools helpful in making diabetes self-managment plans (Ayanlade et al., 2019). They also used ICT to facilitate data logging and as an incentive for better adherence to disease management principles. Studies show that the use of ICT contributes to a statistically significant reduction of glycated haemoglobin (HbA1c) (Lehocki et al., 2015; Aminuddin et al., 2019). Patients that used ICT-based self-management tools also showed better self-efficacy, self-care activities and health related quality of life (Aminuddin et al., 2019). Studies are however divided about the reduction of body weight and BMI (Lehocki et al., 2015; Aminuddin et al., 2019).

\section{Conclusion}

Patients with diabetes are aware of ICT's benefits, importance, and usefulness in self-management, yet its usage remains low. ICT has a positive effect on both patients and health care personnel. It is a matter of fact that ICT is becoming more necessary, due to the fast ageing population and an increasing rate of chronic diseases. Therefore, it is important to know and understand the res- 
ervations patients with diabetes have toward ICT, so they can be successfully eliminated. When developing new and improved ICT we must consider the patients' needs and wishes.

\section{References}

AMINUDDIN, H.B., JIAO, N., JIANG, Y., HONG, J. and WANG, W., 2019. Effectiveness of smartphone-based self-management interventions on self-efficacy, self-care activities, health-related quality of life and clinical outcomes in patients with type 2 diabetes: A systematic review and meta-analysis [in press]. International journal of nursing studies. [viewed 19 April 2020]. Available from: 10.1016/j.ijnurstu.2019.02.003

ARNHOLD, M., QUADE, M. and KIRCH, W., 2014. Mobile applications for diabetics: a systematic review and expert-based usability evaluation considering the special requirements of diabetes patients age 50 years or older [online]. Journal of Medical Internet Research, vol. 16, no. 4, pp. e104. [viewed 3 May 2020]. Available from: http://dx.doi.org/10.2196/jmir.2968

AYANLADE, O.M., OYEBISI, T.O. and KOLAWOLE, B.A., 2019. Health information technology acceptance Framework for diabetes management [online]. Heliyonvol. 5, no. 5, pp. e01735 [viewed 7 May 2020]. Available from: https://www.ncbi.nlm.nih.gov/pmc/articles/PMC6539785/

CDC - CENTERS FOR DISEASE CONTROL AND PREVENTION, 2019. Put the brakes on diabetes complications [online]. [viewed 20 May 2020]. Available from: https://www.cdc.gov/diabetes/library/features/preventcomplications.html

CUI, M., WU, X., MAO, J., WANG, X., NIE, M. and BARENGO, N.C., 2016. T2DM self-management via smartphone applications: a systematic review and meta-analysis [online]. PLoS ONE, vol. 11, no. 11, pp. e0166718. [viewed 4 May 2020]. Available from: http://dx.doi.org/10.1371/journal. pone.0166718

GARDSTEN, C., MORTBERG, C. and BLOMQVIST, K., 2017. Designing an ICTself-management service: suggestions from persons with type 2 diabetes [online]. Health and Technology, vol. 7, pp. 197-206. [viewed 25 May 2020]. Available from: http://dx.doi.org/10.1007/s12553-016-0176-9

GEORGSSON, M. and STAGGERS, N., 2017. Patients' perceptions and experiences of a mHealth

diabetes self-management system [online]. Computers, Informatics, Nursing, vol. 35, no. 3, pp. 122-130. [viewed 5 June 2020]. Available from: http://dx. doi.org/10.1097/CIN.0oooooooooooo296

LEHOCKI, F., JACKULIAK, P., ŽAKOVIČOVA, E. and BACIGAL, T., 2015. ICT based diabetes management system with comprehensive mobile application: Clinical usefulness evaluation. 5th EAI International Conference on Wireless Mobile Communication and Healthcare - „Transform- 
ing healthcare through innovations in mobile and wireless technologies“ [online]. EAI Endorsed Transactions on Bioengineering and Bioinformatics, vol. 16, no. 12, pp. e5. [viewed 1 June 2020]. Available from: http://dx. doi.org/10.4108/eai.14-10-2015.2261966

NYENWE, E.A., JERKINS, T.W., UMPIERREZ, G.E. and KITABCHI, A.E., 2011. Management of type 2 diabetes: evolving strategies for the treatment of patients with type 2 diabetes [online]. Metabolism, vol. 6o, no. 1, pp. 1-23. [viewed 3 May 2020]. Available from: http://dx.doi.org/10.1016/j. metabol.2010.09.010

PERRON, B.E., TAYLOR, H.O., GLASS, J.E. and MARGERUM-LEYS, JO., 2010. Information and communication technologies in social work [online]. Advances in Social Work, vol. 11, no. 2, pp. 67-81.

PETERSEN, P., PATHER, S. and TUCKER, W.D., 2018. User acceptance of ICT for diabetes self-management in the Western Cape, South Africa [online]. [viewed 3 May 2020]. Available from: https://www.researchgate.net/publication/326368952_User_acceptance_of_ICT_for_diabetes_self-management_in_the_Western_Cape_South_Africa

SAEEDI, P., PETERSOHN, I., SALPEA, P., MALANDA, B., KARURANGA, S., UNWIN, N., COLAGIURI, S., GUARIGUATA, L., MOTALA, A.A., OGURTSOVA, K., et al., 2019. Global and regional diabetes prevalence estimates for 2019 and projections for 2030 and 2045: Results from the International Diabetes Federation Diabetes Atlas, 9th edition. [online]. Diabetes Research and Clinical Practice, vol. 157. [viewed 10 June 2020]. Available from: http://dx.doi.org/10.1016/j.diabres.2019.107843

SHIBUTA, T., WAKI, K., TOMIZAWA, N., IGARASHI, A., YAMAMOTOMITANI, N., YAMAGUCHI, S., FUJITA, H., KIMURA, S., FUJIU, K., WAKI, H., et al., 2017. Willingness of patients with diabetes to use an ICT-based self-management tool: a cross-sectional study [online]. BMJ Open Diabetes Research \& Care, vol. 5, pp. eooo322. [viewed 17 April 2020]. Available from: http://dx.doi.org/10.1136/bmjdrc-2016-000322

WHO - WORLD HEALTH ORGANIZATION, 2018. Diabetes. Key facts [online]. [viewed 23 May 2020]. Available from: https://www.who.int/newsroom/fact-sheets/detail/diabetes

YAMAGUCHI, S., WAKI, K., NANNYA, Y., NANGAKU, M., KADOWAKI, T. and OHE, K., 2019. Usage patterns of GlucoNote, a self-management smartphone app, based on ResearchKit for patients with type 2 diabetes and prediabetes [online]. JMIR mHealth and uHealth, vol. 7, no. 4, pp. e132004. [viewed 22 May 2020]. Available from: http://dx.doi. org/10.2196/13204 